\title{
INSTRUCTION TO AUTHORS
}

CARAKA TANI: Journal of Sustainable Agriculture, covers research in the following areas: plant sciences, agronomy, horticultural, plant breeding, soil-plant sciences, pest or disease-plant sciences, animal husbandry, food technology science, and also agricultural extension and communication. The journal also welcomes papers on other related topics provided that such topics are within the context of the broader multi-disciplinary scope of Sustainable Agriculture.

\section{The submission stage}

All articles submitted to journal Caraka Tani are initially assessed by an Editor, who decides whether or not the article is suitable for peer review. Submissions considered suitable for peer review are assigned to one or more independent experts, who assess the article for clarity, validity, and sound methodology. Caraka Tani: Journal of Sustainable Agriculture processes all manuscript through open journal system (OJS). So, we would like to invite authors to submit the manuscript via this link: https://jurnal.uns.ac.id/carakatani.

Letter of manuscript submission will be automatically sent to the authors by Email. The process of the manuscript could be monitored through OJS. Manuscripts will go through the double-blind peer review and editorial review before accepted for publication. Should you have any further questions, please do not hesitate to contact us in this e-mail carakatani@mail.uns.ac.id.

\section{Submission declaration and verification}

Submission of an article implies that the work described has not been published previously (except in the form of an abstract or as part of a published lecture or academic thesis), that it is not under consideration for publication elsewhere. The manuscript should be approved by all authors and tacitly or explicitly by the responsible authorities where the work was carried out. To verify originality, your article may be checked by the originality detection software turnitin or plagiarism checker.

\section{Manuscript Preparation}

Authors must follow guide for authors strictly, failing which the manuscripts would be rejected without review. Editors reserve the right to adjust the style to certain standards of uniformity.

Follow this order when typing manuscripts: Title, Authors, Affiliations, Abstract, Keywords, Introduction, Materials and Methods, Results and Discussion, Conclusions, Acknowledgements, References.

1. The manuscript is written in 11 point Times New Roman font 1.5 space in the A4 paper, wide (2.5 $\mathrm{cm}$ ) margins on white paper. Ensure that each new paragraph is clearly indicated.

2. The following word processor file formats are acceptable for the main manuscript document for all: Microsoft Word (DOC, DOCX) and Rich Text Format (RTF) with size not more than 8MB.

3. The following formats for figure files: Please make sure that artwork files are in an acceptable format (TIFF, EPS or MS Office files) and with the correct resolution. Ensure that each illustration has a caption. Supply captions separately, not attached to the figure. A caption should comprise a brief title (not on the figure itself) and a description of the illustration. Keep text in the illustrations themselves to a minimum but explain all symbols and abbreviations used. Multiple figures can be expressed as one figure (for e.g. 1a, 1b, 1c etc...), while retaining the maximum limit of 6 .

4. The text should be in single-column format. Keep the layout of the text as simple as possible. Most formatting codes will be removed and replaced on processing the article.

5. Page numbers are located at the right top.

6. Figures and Tables are placed in the manuscript (integrated with a whole manuscript). 


\section{Manuscript sections are written in this order, i.e.:}

\section{Title and Author}

Concise and informative. Titles are often used in information-retrieval systems. Avoid abbreviations and formulae where possible. The title should be accurate, unambiguous, specific and informative. It should be written clearly and concisely describing the contents of the research.

Author(s) name(s) and affiliation(s)

A manuscript has the main author and co-authors with a full name of the author and co-authors (no abbreviation), includes affiliation addresses (where the actual work was done) below the names. Each address should be preceded by a numerical superscript corresponding to the same superscript after the name of the author concerned. Give an asterisk $\left({ }^{*}\right)$ in the contact person for correspondence.

\section{Abstract and Keywords}

A concise and factual abstract is required. Each paper should be provided with an abstract of about 150-250 words. The abstract should state briefly the purpose of the research, the principal results and major conclusions. An abstract is often presented separately from the article, so it must be able to stand alone. The abstract must be integrated and independent which is consist of introduction and purpose, methods, results, conclusion, and suggestion. However, the abstract should be written as a single paragraph without these headers. For this reason, References should be avoided. Also, non-standard or uncommon abbreviations should be avoided, but if essential they must be defined at their first mention in the abstract itself. The abstract must be written using 150 until 250 words which have no reference and accompanied keywords.

\section{Keywords}

Keywords are the labels of your manuscript and critical to correct indexing and searching. Keywords should not more than 5 words or phrases in alphabetical order which has not been used in the title. Therefore the keywords should represent the content and highlight of your article. Use only those abbreviations that are firmly established in the field. e.g. DNA.

\section{Introduction}

The Introduction section should explain:

a. The background to the study

b. The aims

c. A summary of the existing literature

d. The reason why the study was necessary

e. As you compose the introduction, think of readers who are not experts in this field. Introduction must be written using 750 until 1000 words.

\section{Materials and Methods}

The methods section should include:

a. Specify the time and place of study in the first section.

b. The aim, design, and setting of the study.

c. The characteristics of participants or description of materials.

d. A clear description of all processes and methodologies employed. Generic names should generally be used. When proprietary brands are used in research, include the brand names in parentheses.

e. The type of statistical analysis used, including a power calculation if appropriate.

f. Studies involving human participants, data or tissue or animals must include statement of ethics approval and consent.

Materials and methods should give reproducible experiment to the readers and must be written using 400 to 600 words. 


\section{Results and Discussions}

Result and discussion must be written in the same part. They should be presented continuously start from the main result to the supporting results and equipped with a discussion. Unit of measurement used should follow the prevailing international system. All figures and tables should be active and editable by an editor. The discussion should explore the significance of the results of the work. Please highlight differences between your results or findings and the previous publications by other researchers.

\section{Conclusions}

Conclusions should only answer the objectives of the research. The conclusion should be explained clearly. Suggestion placed after conclusion contains a recommendation on the research done or an input that can be used directly by the consumer. Conclusions and suggestions should be written less than 100 words and should be written in a paragraph.

\section{Acknowledgements (If any)}

Recognize those who helped in the research, especially funding supporter of your research. Name the person to help you work.

\section{References}

\section{Citation in text}

Cite references in the text by name and year in parentheses. Some examples: It appears to increase the methane production by providing $\mathrm{C}$ sources and decreasing the amount of oxidation-reduction potential ( $\mathrm{Li}, 2007)$. These results are in line with those obtained by Oelbermann and Schiff (2008). By employing the methanothroph bacteria through some oxidation mechanisms, $\mathrm{CH}_{4}$ could be converted into $\mathrm{CO}_{2}$ (Nieder and Benbi, 2008; Thaurer et al., 2008).

Please ensure that every reference cited in the text is also present in the reference list (and vice versa). Any references cited in the abstract must be given in full. Unpublished results and personal communications are not recommended in the reference list, but may be mentioned in the text. If these references are included in the reference list they should follow the standard reference style of the journal and should include a substitution of the publication date with either 'Unpublished results' or 'Personal communication'. Citation of a reference as 'in press' implies that the item has been accepted for publication. All references mentioned must be written based on references arranged from $A$ to $Z$.

\section{Journal abbreviations source}

Journal names should be abbreviated according to the List of Title Word Abbreviations: http://cassi.cas.org/search.jsp.

\section{Example:}

\section{Journal Article}

Zhang, H., Chen, C., Zhu, C., \& Sun, D. 2016. Production Of Bacterial Cellulose By Acetobacter xylinum: Effects Of Carbon/Nitrogen-Ratio On Cell Growth And Metabolite Production. Cellulose Chemistry and Technology. 50(9-10), 997-1003.

\section{Book}

Deublein, D., \& Steinhauser, A. 2008. Biogas from Waste and Renewable Resources. Mörlenbach, Germany: WILEY-VCH Vewrlag GmbH \& Co. KgaA. https://doi.org/10.1002/9783527621705

\section{Edited Book}

Taherzadeh, M. J., \& Karimi, K. 2011. Fermentation inhibitors in ethanol processes and different strategies to reduce their effects. Biofuels (1st ed.). Elsevier Inc. https://doi.org/10.1016/B978-012-385099-7.00012-7 


\section{Dissertation or Thesis}

Forgács, G. 2012. Biogas Production from Citrus Wastes and Chicken Feather: Pretreatment and Co-digestion (Doctoral Thesis). Göteborg, Sweden: Chalmers University of Technology. Retrieved from http://publications.lib.chalmers.se/records/fulltext/157608.pdf

Web

Central Bureau Statistics of Indonesia. 2015. Produksi buah-buahan dan sayuran tahunan di Indonesia. Online: http://www.bps.go.id/site/pilihdata.

${ }^{*}$ References should use a reference management tool such as Mendeley/Zotero/Endnote.

\section{Template file could be downloaded in the website:}

https://goo.gl/jUj929

\section{Author Fees}

This journal charges the following author fee. If this paper is accepted for publication, you will be asked to fulfill the publication fee of your article.

Article Publication Fee: 250,000.00 IDR

If the author needs more printed version of the journal, the author can pay the print costs of $50,000.00$ IDR per copy. 
PARTNERS

Google Crossref BASE Bielefeld Academic Search Engine PKP INDEX

\author{
ชิ MENDELEY
}




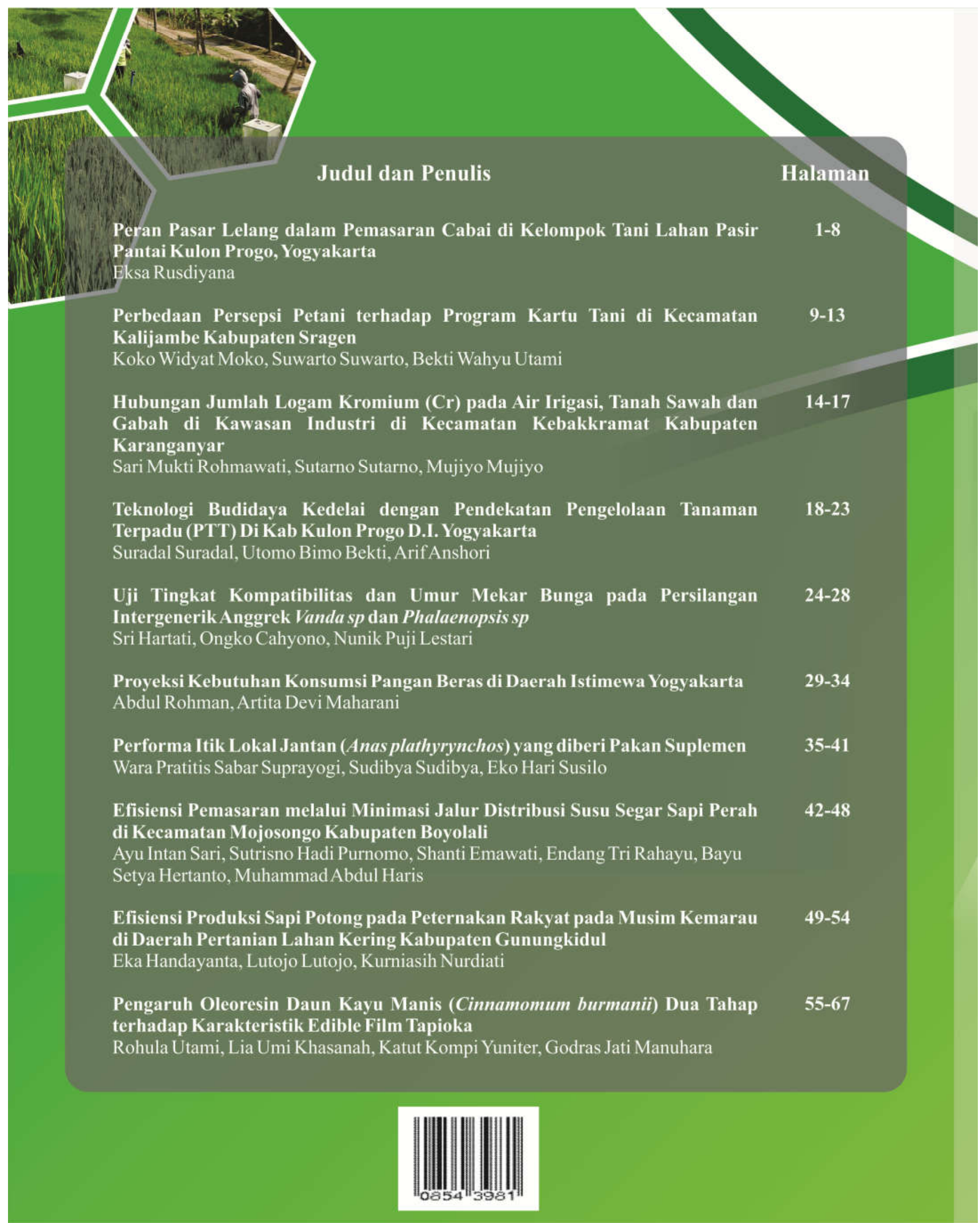

CarakaTaní Journal of Sustainable Agriculture
@ carakatani@mail.uns.ac.id https://jurnal.uns.ac.id/carakatani
(C) (0271) 637457

\& Fakultas Pertanian, Universitas Sebelas Maret JI. Ir. Sutami No.36A, Jebres, Surakarta 